\title{
BMJ Open Prospective, population-based study of occupational movements and postures of the neck as risk factors for cervical disc herniation
}

\author{
Jonathan Aavang Petersen (D) , ${ }^{1}$ Charlotte Brauer, ${ }^{1}$ Lau Caspar Thygesen, ${ }^{2}$ \\ Esben Meulengracht Flachs, ${ }^{1}$ Christina Bach Lund, ${ }^{1}$ Jane Frølund Thomsen ${ }^{1}$
}

To cite: Petersen JA, Brauer C, Thygesen LC, et al. Prospective, population-based study of occupational movements and postures of the neck as risk factors for cervical disc herniation. BMJ Open 2022;12:e053999. doi:10.1136/ bmjopen-2021-053999

- Prepublication history for this paper is available online. To view these files, please visit the journal online (http://dx.doi. org/10.1136/bmjopen-2021 053999).

Received 01 June 2021 Accepted 19 January 2022

Check for updates

(C) Author(s) (or their employer(s)) 2022. Re-use permitted under CC BY-NC. No commercial re-use. See rights and permissions. Published by BMJ.

${ }^{1}$ Department of Occupational and Environmental Medicine, Bispebjerg Hospital, Kobenhavn, Denmark

${ }^{2}$ National Institute of Public Health, University of Southern Denmark, Odense, Denmark

Correspondence to

Dr Jonathan Aavang Petersen; jonathanaavang@hotmail.com

\section{ABSTRACT}

Objective We studied the associations between

objectively measured occupational neck exposures in a job exposure matrix (JEM) and cervical disc herniation (CDH).

Design A cohort study of Danish workers who ever held at least one of 29 jobs (eg, dentists, hairdressers, childcare, carpenters) from 1981 to 2016 was formed. Representative whole work-day inclinometric measurements from previous studies using triaxial accelerometers measuring neck angular velocity and posture of the neck were used as exposure in a JEM. Job titles were retrieved from the Danish Occupational Cohort with eXposure data database. The risk of $\mathrm{CDH}$ by quintiles of cumulated exposure was assessed by incidence rate ratios (IRR), adjusted for age, sex, calendar-year, previous lumbar disc herniation and educational level, using Poisson regression models.

Setting Nationwide Danish registers.

Participants 852625 Danish workers within 29 different job-titles.

Outcome measures First diagnosis of $\mathrm{CDH}$ was retrieved from the Danish National Patient Register.

Results We found 14000 cases of $\mathrm{CDH}$ during 20.2 million person-years of follow-up. Increasing levels of neck angular velocity showed a decreasing risk with IRR 0.90 (95\% Cl 0.86 to 0.95 ) when the highest level of cumulative exposure (dynamic work) was compared with the lowest (static work). Similar results were found for extension and flexion of the neck, though not statistically significant for extension. Multiple sensitivity analyses did not change the results.

Conclusion In this large register-based study based on a JEM, we found no evidence of an increased risk of $\mathrm{CDH}$ with increasing cumulated angular velocity, flexion or extension of the neck. Factors other than occupational dynamic neck movements and bent neck position seem to be important in the development of $\mathrm{CDH}$.

\section{INTRODUCTION}

Cervical disc herniation $(\mathrm{CDH})$ is a common cause of localised neck pain and cervical radiculopathy and develops from the degenerative rupture of the annulus fibrosis and the protrusion of the gel-like nucleus pulposus with resulting compression and irritation
Strengths and limitations of this study

- In this prospective study, we used national registers to form a large cohort of persons to investigate the associations between measured neck exposures at work and cervical disc herniation, adjusted for confounders such as age, sex and lumbar disc herniation.

- To avoid recall bias and increase precision of the case definition, we used representative measurements in a job exposure matrix and national patient registers.

- We were able to follow the cohort for a long period of time. Thus, we could apply different time aspects of exposure.

- Limitations of the study are related to the heterogeneity of actual exposure within the job groups, periods of time in unmeasured jobs, and lack of measurements of other potential occupational factors.

of spinal nerves. ${ }^{1}$ Based on MRI, different kinds of hernias can be identified as protrusions, extrusions and sequestrations, however, imaging results should be interpreted with caution, as disc pathologies among asymptomatic persons are not uncommon. ${ }^{23}$ The reported incidences of $\mathrm{CDH}$ or cervical radiculopathy in different populations vary considerably, ranging from 10.7 to 176 per 100000 person-years, with a peak incidence in the fifth decade of age and a tendency of an increased risk in women. ${ }^{4-7}$

Some evidence exists suggesting an association between neck problems and neck flexion. ${ }^{8}$ The knowledge regarding association between neck postural exposures and $\mathrm{CDH}$ is scarce. Although age and genetics are the main risk factors, various occupational exposures have been suggested as causal factors for $\mathrm{CDH} .{ }^{2}$ Some studies have suggested that civil servants, dentists, pilots, astronauts, physicians and athletes are at increased risk 
of $\mathrm{CDH}$ due to occupational exposure, but only a few with a prospective design.$^{9-14}$ In two Danish, prospective and register-based studies, an increased risk of $\mathrm{CDH}$ and other dorsopathies was found among professional drivers compared with the general working population. ${ }^{15}{ }^{16}$ In a cross-sectional study of multiple job functions using inclinometric measurements, no significant association was found between head positions or velocity and cervical syndrome, defined clinically as pain radiating from the neck to the upper extremity in combination with objective findings. ${ }^{17}$

In contrast to lumbar spine segments, the cervical spine is not exposed to great weight-bearing exposures such as lifting, but to other extrinsic exposures such as static load, whole body vibration, repetitive movements, G-forces or extreme postures. The mechanism of herniation may involve increasing dehydration and degeneration with age and exposure, thus increasing the compressive force on the annulus with resulting microtears and rupture. ${ }^{1418}$ In an in vivo study, contributions of neck movements from various segments to the compression forces depended on the position of the neck. ${ }^{19}$ During maximal flexion and extension of the neck, the disc deformation differed between segment levels and location and could exceed $70 \%$ of the disc height in the cervical spine discs. ${ }^{20}$ Thus, it is compelling to hypothesise that different patterns of occupational movements and position of the head and neck might influence the disease pattern of the cervical intervertebral disc.

To our knowledge, no large epidemiological, prospective cohort studies of CDH based on technical measurements within several different jobs have been conducted.

The aim of this study was to explore the associations between objectively measured movements and positions of the neck in a Job Exposure Matrix (JEM) and the risk of $\mathrm{CDH}$ in a large, prospective, population-based cohort.

\section{MATERIALS AND METHODS \\ Study population}

We established a cohort of persons born in Denmark between 1 January 1940 and 31 December 1979 and alive in 2003 by using the Danish Civil registration system. ${ }^{21}$ This allowed for linkage to other national registers in Statistics Denmark with information on sex, date of birth, emigration, immigration and death. We retrieved annual information from 1 January 1981 to 31 December 2016 on their main job title by using the Occupation and Industry Register in the Danish Occupational Cohort with eXposure (DOC*X)-database based on the Danish version of the International Standard Classification of Occupation (D-ISCO) codes and the industry codes of the Danish Industrial Classification of All Economic Activities. ${ }^{22} 23$ Also, registers of the highest fulfilled educational level in the Danish version of the International Standard Classification of Education were used. ${ }^{24}$

\section{Exposure assignments}

Exposure was assigned by a JEM which is a cross-tabulation of job titles and occupational exposures. ${ }^{25}$

We used the results of inclinometric measurements from studies pooled in the EMINGO-database (ElectroMyography, INclinometry and GOniometry), hosted by the Department of Occupational and Environmental Medicine, Lund, Sweden. Thirty-four job titles with neck measurements were available. Of these, 26 were measured in Denmark and 8 in Sweden, with the use of identical measurement protocols and equipment. The job functions in the Swedish measurements were comparable to Danish conditions.

The measurement programme has previously been described in detail. ${ }^{26}{ }^{27}$ Briefly, companies and employees with exposures believed to be typical for the job titles selected for the study were asked to participate. The jobs were chosen to represent large exposure contrasts and jobs of both sexes. Measurements were performed on healthy, right-handed participants with no musculoskeletal complaints. Measurements in at least 10 men or 10 women or both (if job functions differed with sex) were considered to provide accurate job exposure estimates. ${ }^{28}$

Whole day inclinometric measurements were performed using triaxial accelerometers. The inclinometers were placed as per protocol on the forehead and upper back. Data were recorded with a sampling rate of $20 \mathrm{~Hz}$ using data loggers (Logger Teknologi HB, Åkarp, Sweden). ${ }^{29}$ Analyses were made using EMINGO, a programme developed by the Department of Occupational and Environmental Medicine, Lund, Sweden. For each participant in the Emingo database, excluding breaks, neck movements and positions were characterised by the absolute median angular velocity $(\% / s)$ and 1 st and 90th percentile of flexion/extension. The neck's contribution to the movements and positions was calculated by subtraction of upper back measurements from head measurements. ${ }^{30}$ These measures were chosen as they have been found to represent separate exposure dimensions with low correlation, and the 1st percentile of neck position is a measure of extension (lower values=more extended positions), and the 90th percentile is a measure of flexion (higher values=more flexed position).$^{31}$ Data on lateral bending or axial torque were not available. Duration of measurements (excluding breaks) ranged from 3.1 to 6.9 hours. For each job title, the mean of the median angular velocity and 1 st and 90 th percentile of flexion/extension was used as the final value in the JEM.

We were unable to define 2 of the 34 jobs with acceptable accuracy in the D-ISCO classification (scaffolders and storage workers). Information on neck measurements was unavailable in 3 jobs (office workers, cleaning assistants and slaughterhouse workers), leaving 29 different job titles in our study.

\section{Outcome and health related confounders}

The Danish National Patient Register (DNPR) holds information about all patient contacts to all Danish hospitals 
Table 1 Definitions of diagnoses in ICD-8 and ICD-10

Cervical disc ICD-8 codes 725.00, 725.01 and 725.09

herniation:

and ICD-10 codes M50.0-50.9.

\begin{tabular}{|c|c|}
\hline $\begin{array}{l}\text { Lumbar disc } \\
\text { herniation: }\end{array}$ & $\begin{array}{l}\text { ICD-8 codes } 725.10,825.11 \text { and } 825.19 \\
\text { and ICD-10 codes M51-513B, M51.8-9. }\end{array}$ \\
\hline $\begin{array}{l}\text { Trauma to the } \\
\text { neck: }\end{array}$ & $\begin{array}{l}\text { ICD-8 codes; 805.00-805.09, 806.00- } \\
806.10,806.90,839.10,958.00-958.10, \\
958.20-958.22,958.28-958.29 \text { and ICD-10 } \\
\text { codes; S12-127, S129, S130, S134B-C, } \\
\text { S14-141B, S142 }\end{array}$ \\
\hline
\end{tabular}

ICD, International Classification of Diseases.

since 1977 (inpatient diagnoses from 1977 and outpatient diagnoses from 1995). ${ }^{32}$ Cases were identified in DNPR by a primary diagnosis (hospital discharge codes, decided by the treating clinician and usually supported by diagnostic imaging) of $\mathrm{CDH}$. The International Classification of Diseases (ICD) 8th (ICD-8) and 10th (ICD-10) revisions were used. We used ICD-8 codes 725.00, 725.01 and 725.09 and ICD-10 codes M50.0-50.9 to identify 'Cervical disc disorders' including herniations. ${ }^{33} 34$ We developed a directed acyclic graph to determine which confounders to include in our final model containing age, sex, calendar year, smoking, body mass index (BMI), extreme G-forces, sports activities, educational level and lumbar herniated disc (as a proxy for genetic influences). Information on all confounders were available for all persons in the cohort except for smoking, BMI, extreme G-forces and sports activities. Lumbar herniated disc was treated as a risk factor from 1 January of year of diagnosis (see table 1) and onwards.

\section{Statistical analysis}

The cohort subjects was followed from 1 January 1981 or the year of entry in one of the 29 jobs if they were above the age of 18 until the date of $\mathrm{CDH}$, trauma to the neck (see table 1), emigration, death or 1 January 2017, whichever came first. If first information on migration was an immigration after the age of 18, the cohort subjects were excluded. We allowed emigration periods of $<1$ year among cohort subjects aged 18-30, but longer emigration periods or emigration after 30 years of age was basis for censoring. This allowed for young cohort subjects to travel abroad during a potential time of education. We excluded cohort subjects with a $\mathrm{CDH}$ diagnosis before entry to the cohort.

Based on the above, for each cohort subject we calculated the proportion of time spent in Denmark in each calendar year to define the job-specific exposure time. This proportion was multiplied by the calculated neck exposures, creating an annual measure of exposure. The yearly total cumulative exposure was calculated by summing up exposures of all previous years. Years spent in jobs without measured exposure were given the lowest value in the JEM exposure. The main analyses included the annual cumulated exposure-level categorised by quintiles and as such cannot meaningfully be interpreted in terms of absolute ranges of degrees or degrees per second.

As sensitivity analyses, we examined the 10-year, 5-year and 2-year cumulated annual exposure (again divided into quintiles) in order to disentangle effect of age and exposure. We examined the age (40-55th year of age)-restricted and sex (males/females only)-restricted exposures and the effect of restricting the outcome to only the diagnoses M50, 50.0, 50.1, 50.2, 72500, 72501 (herniations). We also restricted the cohort to the period 1995-2016, where information on diagnoses is thought to be the most complete as it is based on both inpatient and outpatient information. A sub-population of cohort subjects aged under 30 years at entry was formed to investigate the impact of entry with unknown exposure. Finally, years with job titles without measured exposure were given the respective mean of each of the nine main D-ISCO groups, calculated from the measured jobs represented in the main D-ISCO group. This analysis was only possible with angular velocity, as means of positions were almost identical across main D-ISCO groups.

Poisson regression models were used to estimate incidence rate ratios (IRRs) of $\mathrm{CDH}$ in relation to cumulated neck angular velocity, extension and flexion of the neck. The logarithm of risk time was used as offset value. Spearman rank test examined correlations between exposure values for the three different exposures.

We report results as crude and adjusted IRRs with 95\% CI. Adjustments were made for sex, age, calendar year (1975-1979, 1980-1984, 1985-1989, 1990-1994, 19951999, 2000-2004, 2005-2009, 2010-2014, 2015), lumbar herniated disc and educational level (elementary, high school, vocational, higher or unknown).

Data were analysed using SAS V.9.4 (SAS Institute).

\section{Patient and public involvement}

Patients or the general public were not involved in the design or development of the study.

\section{RESULTS \\ Demographics}

A total of 852625 subjects were included in the cohort, see figure 1 . Values of neck angular velocity ranged from $4.9^{\circ} \% \mathrm{~s}$ to $24.7 \% \mathrm{~s}$ between job titles, with dentists and bank assistants as the jobs with lowest measurements and garbage collectors with the highest. Range of extension of the neck was $-16.4^{\circ}$ to $-44.6^{\circ}$ where electronical workers and truck drivers had the least extended neck and carpenters had the most extended neck. Neck flexion ranged from $13.5^{\circ}$ to $42.6^{\circ}$, where laundry workers represented the highest values (table 2).

Median age at entry was 28.2 (22.6-36.7) and varied between jobs from 22.2 years (car mechanics) to 37.6 years (garbage collectors). Major contributors to total risk time were bank assistants and nurses and smallest contributions came from cardboard workers (table 2). A total 


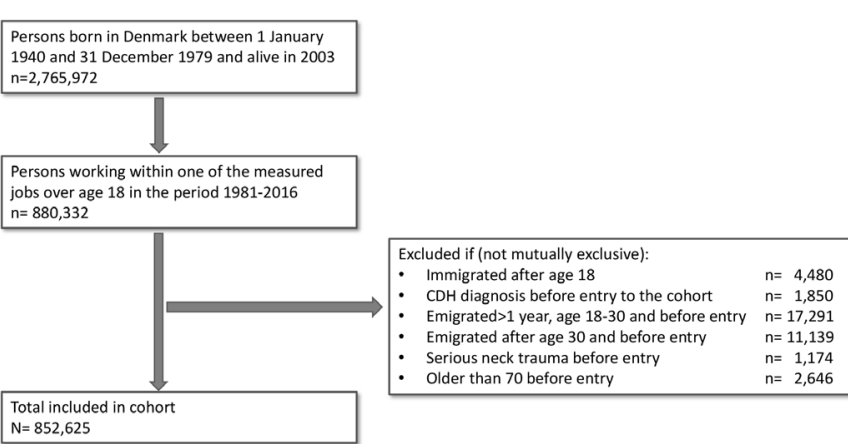

Figure 1 Flow chart of the creation of the cohort. $\mathrm{CDH}$, cervical disc herniation.

of 8065926 out of $20235440(40 \%)$ person years had known exposure, that is, the person worked in one of the measured jobs.

The correlation between angular velocity and 1st and 90th percentile of flexion/extension was low with Spearman correlation coefficient of -0.007 and 0.147 , respectively. First and 90th percentile of flexion/extension were not correlated (Spearman correlation coefficient of 0.15 ).

Mean age varied considerably according to levels of exposure due to the nature of cumulating exposure. Also, the sex ratio differed over levels of angular velocity with an overweight of men with increasing levels of exposure (table 3).

A similar pattern was found for flexion whereas a more equal distribution of sexes was found in levels of exposure of extension (results not shown).

\section{Main results}

We found 14000 cases of CDH. Crude IRRs for angular velocity, extension and flexion showed a steady increase with levels of exposure (table 4).

When adjusted for age, agexage, sex and calendar-year, this pattern was almost reversed with significantly reduced IRRs with increasing angular velocity and flexion. The same pattern was seen for extension though not statistically significant. Further adjustment for LDH and education did not change the estimates.

We found a consistently lower fully adjusted IRR of $\mathrm{CDH}$ among men compared with women across the exposures (IRR $0.82,95 \%$ CI 0.79 to 0.85 ) and a consistently higher risk of $\mathrm{CDH}$ among those with a previous lumbar herniated disc (IRR 4.85, 95\% CI 4.64 to 5.07). Also, IRRs increased steadily with age until 46th year and then decreased with increasing age.

\section{Sensitivity analyses}

Ten-year, 5-year and 2-year cumulated exposures of extension and flexion showed a similar pattern to the main analyses, with no exposure-response pattern observed. This also applied to angular velocity, although 2-year cumulated exposure had a steep increase in IRR for first to second level of exposure and then a gradual decrease from level 2 to level 5 (data not shown).
Neither the use of a more restrictive diagnosis, restricting on age or sex changed this pattern. Further, a similar pattern was observed when restricting the cohort to the period 1995-2016 and in a subpopulation of persons aged under 30 years at entry. Using the respective mean of D-ISCO main groups in years not in a measured job increased the years with differentiated exposure from $40 \%$ to $81 \%$ attenuated the results towards 1 .

\section{DISCUSSION}

In this large cohort study with objectively measured neck postural and movement exposures in a JEM, we found no evidence of a positive association or exposure-response association between increasing neck movements or positions and incidence of CDH. Some evidence of a protective effect of highest cumulated exposure was found, however, such small estimates just below 1.0 should be cautiously interpreted due to a possible healthy worker effect. In general, multiple sensitivity analyses did not change this result and the effect was the same for both sexes. We found a consistently higher risk among women compared with men. Also, a previous diagnosis of lumbar disc herniation increased the risk of a $\mathrm{CDH}$ more than fourfold. Age was a strong risk factor with peak incidence in the fifth decade.

\section{Strengths and limitations}

The use of a JEM with technical measurements in a prospective design spanning up to 35 years gives the advantage of minimising the risk of information bias compared with individual-based self-report methods. ${ }^{25}$ Another strength is the use of high-quality Danish registers regarding diagnoses and employment data from DOC*X, which have shown high validity. ${ }^{25}$

However, a JEM is prone to misclassification of exposure, as some people with the same job title will not have identical exposures to physical workloads or the measurements might not be representative for the job function. Within a job group some individuals may have more extreme or unususal exposures than the group on average. Using the mean as the group exposure level will then tend to attenuate the true associations. We cannot exclude a true association between exposure and outcome, but we expect the residual confounding effect to be small as sensitivity analyses did not change the results. $^{35}$

Using cumulative exposure is considered the preferred exposure metric when investigating chronic diseases, and the biomechanical background for development of $\mathrm{CDH}$ is thought to be cumulated forces and microradial tears in the annulus, though also acute injury (peak exposures) can cause herniations. ${ }^{143637}$ The JEM only included cumulated flexion/extension and velocity, and is unable to test theories of acute injuries or rotational motion or axial torque/twist proposed by cadaveric studies. ${ }^{38}$ Various movements affect structures of the spine differently and the forces required to cause injury are influenced by 
Table 2 Characteristics of the cohort of all persons born in Denmark 1940-1979, living in Denmark January 2003 ever working within one of the measured jobs after the age 18 in the period 1981-2016

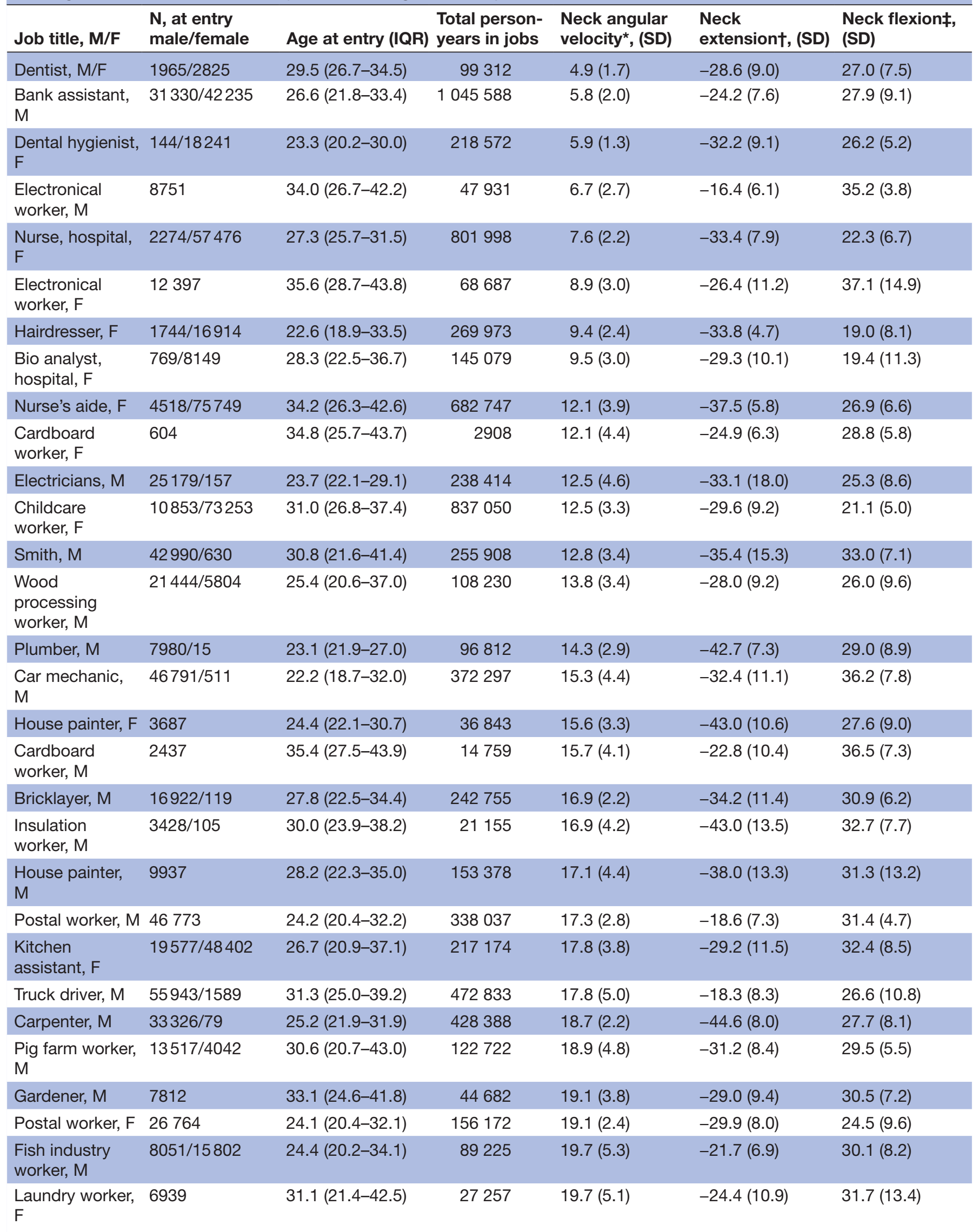


Table 2 Continued

\begin{tabular}{|c|c|c|c|c|c|c|}
\hline Job title, M/F & $\begin{array}{l}\mathrm{N} \text {, at entry } \\
\text { male/female }\end{array}$ & Age at entry (IQR) & $\begin{array}{l}\text { Total person- } \\
\text { years in jobs }\end{array}$ & $\begin{array}{l}\text { Neck angular } \\
\text { velocity*, (SD) }\end{array}$ & $\begin{array}{l}\text { Neck } \\
\text { extensiont, (SD) }\end{array}$ & $\begin{array}{l}\text { Neck flexion } \neq \text {, } \\
\text { (SD) }\end{array}$ \\
\hline $\begin{array}{l}\text { Fork-lift } \\
\text { operator, M }\end{array}$ & $22805 / 1882$ & $35.9(28.2-44.9)$ & 110340 & $21.3(5.9)$ & $-27.7(8.3)$ & $13.5(4.8)$ \\
\hline Gardener, F & 1875 & $27.3(21.8-35.7)$ & 7072 & $21.6(3.9)$ & $-38.8(8.1)$ & $26.0(9.5)$ \\
\hline $\begin{array}{l}\text { Construction } \\
\text { worker, M }\end{array}$ & $53392 / 845$ & 29.8 (23.3-38.4) & 256932 & $22.3(7.2)$ & $-31.0(8.5)$ & $36.1(8.9)$ \\
\hline $\begin{array}{l}\text { Garbage } \\
\text { collector, M }\end{array}$ & $6889 / 250$ & $37.6(30.9-45.5)$ & 27842 & $24.7(5.2)$ & $-25.7(6.5)$ & $18.4(8.0)$ \\
\hline Total & $455117 / 397508$ & $28.2(22.6-36.7)$ & 8065926 & & & \\
\hline
\end{tabular}

Jobs are arranged according to increasing neck angular velocity.

${ }^{*}$ Fiftieth percentile of angular velocity $(\% / s)$.

†First percentile of flexion/extension $\left({ }^{\circ}\right)$.

$\ddagger$ Ninetieth percentile of flexion/extension $\left({ }^{\circ}\right)$.

$\mathrm{M} / \mathrm{F}$, measured on males or females; $\mathrm{N}$, number.

how the combinations of movement are performed.$^{39}$ In this case, our method may be too simple. We used the median angular velocity $(\% / \mathrm{s})$ and 1 st and $90^{\text {th }}$ percentile of flexion/extension as they have been found to represent separate exposure dimensions with low correlation with regards to head measurements. ${ }^{31}$ Also, we used the difference between simultaneous head and upper back measurements to define isolated neck exposures. ${ }^{40}$ Thus, the neck movements were not confounded by back movements. In this study, a low correlation between all exposure variables was confirmed.

Only $40 \%$ of the total person years could be assigned an exposure value leaving $60 \%$ of the time to unknown exposure. This might have diluted the results. However, sensitivity analyses with 10-year, 5-year and 2-year cumulated exposures did not change the overall result. We used a combination of job title and industry code to define our cohort in order to increase the possibility that the group-based measurements represented the actual job function. Person years without exposure could then be unemployment or time working in a different job setting or industry not represented by the measurements. Using the measured means of the job groups within the nine main D-ISCO groups doubled the percentage of measured exposure time but did not change the results. From table 2, it is apparent that the age of entry allows for exposure before entry to the cohort. We had data on job exposure since 1981, and exposures before this is unknown. Exposure difference could be significant, however, sensitivity analyses based on shorter follow-up (2 years, 5 years and 10 years) yielded the same results.

An unknown proportion of the total number of $\mathrm{CDH}$ in the population was managed in the primary health sector and could not be included in our study. A Danish study estimated that around 10000 patients in Denmark seek medical care due to cervical radiculopathy every year,

\begin{tabular}{|c|c|c|c|c|c|c|}
\hline Cumulated angular velocity & $\begin{array}{l}\text { Level } \\
1^{*} \text { (lowest) }\end{array}$ & Level $2^{*}$ & Level $3^{*}$ & Level $4^{*}$ & $\begin{array}{l}\text { Level 5*} \\
\text { (highest) }\end{array}$ & Total \\
\hline Person years & 4051052 & 4054683 & 4052995 & 4044577 & 4032033 & 20235440 \\
\hline Men, \% & 47.9 & 50.8 & 51.7 & 53.4 & 66.2 & 53.4 \\
\hline Women, \% & 52.1 & 49.2 & 48.3 & 46.6 & 33.8 & 46.6 \\
\hline Mean age (IQR) & $\begin{array}{l}31.8 \\
(24.4-37.3)\end{array}$ & $\begin{array}{l}36.6 \\
(29.8-41.8)\end{array}$ & $\begin{array}{l}41.4 \\
(35.2-46.7)\end{array}$ & $\begin{array}{l}46.9 \\
(40.2-53.3)\end{array}$ & $\begin{array}{l}51.2 \\
(44.5-58.0)\end{array}$ & $\begin{array}{l}41.6 \\
(32.7-49.9)\end{array}$ \\
\hline Lumbar disc herniation, cases & 5672 & 8112 & 9659 & 10323 & 10436 & 44202 \\
\hline Men, \% & 49.5 & 53.4 & 53.8 & 54.8 & 68.2 & 56.8 \\
\hline Women, \% & 50.5 & 46.6 & 46.2 & 45.2 & 31.8 & 43.2 \\
\hline Lumbar disc herniation, IR & 14.0 & 20.0 & 23.8 & 25.5 & 25.9 & 21.8 \\
\hline
\end{tabular}

Shown for angular velocity.

*Based on quintiles of cumulative exposure in the study population.

$\mathrm{IR}$, incidence rate. 
Table 4 Associations between levels of cumulated neck exposures and cervical herniated disc disorders, IR per 10000 person-years, crude and adjusted IRR $(95 \% \mathrm{Cl})$

\begin{tabular}{|c|c|c|c|c|c|c|}
\hline & Level $1^{*}$ & Level $2^{\star}$ & Level 3* & Level $4^{\star}$ & Level 5* & Total \\
\hline $\mathrm{CDH}$, cases & 1355 & 2152 & 3131 & 3655 & 3707 & 14000 \\
\hline IR & 3.3 & 5.3 & 7.7 & 9.0 & 9.2 & 6.9 \\
\hline IRR, crude & 1 (ref) & 1.59 (1.48 to 1.70$)$ & 2.31 (2.17 to 2.46 ) & 2.70 (2.54 to 2.88$)$ & 2.75 (2.58 to 2.93 ) & \\
\hline IRR, fully adjusted $\ddagger$ & 1 (ref) & 0.99 (0.92 to 1.06$)$ & 0.98 (0.91 to 1.04$)$ & $0.92(0.86$ to 0.98$)$ & 0.90 (0.84 to 0.96$)$ & \\
\hline \multicolumn{7}{|l|}{ Cumulated extension } \\
\hline $\mathrm{CDH}$, cases & 1305 & 2055 & 2973 & 3707 & 3960 & 14000 \\
\hline Person years & 4047233 & 4057605 & 4054817 & 4047237 & 4028549 & 20235440 \\
\hline IR & 3.2 & 5.1 & 7.3 & 9.2 & 9.8 & 6.9 \\
\hline \multicolumn{7}{|l|}{ Cumulated flexion } \\
\hline $\mathrm{CDH}$, cases & 1360 & 2086 & 3037 & 3784 & 3733 & 14000 \\
\hline Person years & 4015039 & 4077672 & 4065870 & 4048840 & 4028019 & 20235440 \\
\hline IR & 3.4 & 5.1 & 7.5 & 9.3 & 9.3 & 6.9 \\
\hline IRR, crude & 1 (ref) & 1.51 (1.41 to 1.62$)$ & 2.21 (2.07 to 2.35 ) & 2.76 (2.59 to 2.94$)$ & 2.74 (2.57 to 2.91$)$ & \\
\hline IRR, adjusted $\dagger$ & 1 (ref) & 1.03 (0.96 to 1.10$)$ & 1.00 (0.94 to 1.07$)$ & $0.93(0.87$ to 0.99$)$ & 0.85 (0.79 to 0.91$)$ & \\
\hline IRR, fully adjustedł & 1 (ref) & 1.03 (0.96 to 1.10$)$ & 1.00 (0.94 to 1.07$)$ & $0.94(0.88$ to 1.00$)$ & 0.87 (0.81 to 0.93$)$ & \\
\hline
\end{tabular}

Estimates in bold are significant at $\mathrm{P}<0.05$.

${ }^{*}$ Based on quintiles of cumulative exposure in the study population.

†Adjusted for age, agexage, sex and calendar-year.

$\ddagger$ Adjusted for age, agexage, sex, calendar-year, lumbar disc herniation and education.

$\mathrm{CDH}$, cervical disc herniation; IR, Incidence rate; IRR, Incidence rate ratio.

whereof a proportion of these will be due to $\mathrm{CDH} .{ }^{41}$ The study's incidence rate $(6.9 / 10000$ person years) is more than a factor of 10 higher than Finnish and Norwegian surgical incidence rates, most likely due to the fact that most patients with CHD will recover within 4-6 months without surgery and never require contact with hospitals. ${ }^{133}$ However, this should not affect the associations as we are not aware of any evidence for a difference in pathogenesis for severe and minor $\mathrm{CDH}$.

\section{Interpretation}

The recent review by Zielinska et al concluded, that intervertebral disc disease is a multiple-causative disease including mainly genetic factors in combination with ageing, high BMI and smoking. ${ }^{2}$ The review also suggested that the environmental factors interact with genetic factors and accelerate the process of degeneration, but conclude that there is no research in which the influence of environmental factors is recognised as independent without the influence of genetic factors. ${ }^{2}$ Our results are in line with this conclusion and find no major influence of neck postural exposures on incidence of $\mathrm{CDH}$.
Other longitudinal studies have found an increased risk of hospitalisations for $\mathrm{CDH}$ among male professional drivers compared with the general population using job titles in the Danish registers as exposure. ${ }^{16}$ Causal theories included whole body vibration, frequent road shocks, higher rate of whiplash injury and repeated twisting and deacceleration and acceleration of the neck. Our study does not confirm the theory of neck movements and postural exposure as cause of $\mathrm{CDH}$ and was unable to test whole body vibrations or accidents. When including all outpatient treatment and emergency ward treatment of $\mathrm{CDH}$, Jensen $e t a l^{15}$ found a significantly increased risk of other dorsopathies and dorsalgia but not of cervical disc disorders among truck drivers compared with the general working population. Our study populations were based on the same registers and might overlap to some degree, although we do not expect the overlap to be complete due to different methods of sampling. Our truck drivers were among the lowest exposed for neck extension and in the lower and middle part of neck flexion and velocity, respectively. As such, our study did not find truck drivers to be at increased risk. 
In the cohort study investigating risk of $\mathrm{CDH}$ among physicians by Liu et al, a higher crude OR among physicians compared with non-physicians and non-health care professionals was found. ${ }^{13}$ The effect became insignificant after adjustments for age and sex, as in our study. Similar results were found when comparing dentists to the general population and other healthcare professionals. ${ }^{10}$ We found a slight tendency towards a higher risk among the lowest levels of angular velocity, and dentists were in general placed in this category. However, the same dentists were placed in the middle part of neck extension and flexion where no excess risk was found.

One study used inclinometry of the head in relation to neck pain in a cross-sectional design with subjective complaints and clinical diagnoses such as cervical syndrome (defined as radiating pain, decreased sensibility and muscle weakness). ${ }^{17}$ This was partly the same measurements as in our study and they found that increasing inclination in the 90th percentile was significantly associated with only tension neck syndrome (defined as neck pain, fatigue and stiffness) and not with cervical syndrome. ${ }^{17}$ Selection of healthy workers may have affected the results as prevalence of some diagnoses decreased with increasing employment time.

We found a pattern of peak risk of CHD in the 46th year and thereafter a decreasing trend with age. This is in line with other studies although our finding might have been influenced by the relative young age of the cohort. ${ }^{4-6}$ Also, we found a consistently much higher risk of cervical herniated disc among those with a prior lumbar herniated disc (IRR 4.91, 95\% CI 4.73 to 5.1). This may be due to a shared cause due to genetics. ${ }^{42}$

Based on the results of this study, the clinical implications could be that in order to reduce the incidence of $\mathrm{CDH}$ attention should be on factors other than dynamic neck movements and bent neck positions. In this way, we find no modifiable risk factors to intervene on. Perhaps the cervical discs can withstand the impact of normal movements and positions of the neck without increasing the risk of herniation. However, the 29 job titles with representative inclinometric measurements of the neck only constitute a small proportion of the total jobs in the D-ISCO 88 . We did find considerable exposure contrast and range in the measurements of the included jobs. Thus, if the measurements represent the actual exposure of the job group accurately, the use of a JEM within a register-based cohort gives great power to the study and no risk of information bias. Inclusion of additional job titles in the JEM should further improve the precision of the exposure assessment, and some jobs may have more extreme measures of velocity or positions that may change our finding of no causal effect of neck position or movement on CDH. Also, a task-based exposure matrix may identify occupational risk factors that a JEM is unable to. ${ }^{43}$

\section{CONCLUSION}

We found no evidence of a positive association or an exposure-response effect of neck movements or neck positions on the risk of $\mathrm{CDH}$ when using a JEM based on representative inclinometric measurements of the neck and register-based outcome measures.

Contributors JFT, CBL, LCT, CB, EMF and JAP designed the study and JAP, JFT and EMF acquired the data; JAP and EMF analysed the data and JAP drafted the manuscript; JFT, LCT, CBL, CB, EMF and JAP interpreted the data. All authors critically reviewed the draft for important intellectual content. All authors agreed to be accountable for all aspects of the work in ensuring that questions related to the accuracy or integrity of any part of the work are appropriately investigated and resolved. JAP accepts full responsibility for the finished work and/or the conduct of the study as guarantor, had access to the data, and controlled the decision to publish

Funding This study was supported by grants from the Danish Working environment research Fund (grant \# 20175100917) and The Research Centre for Hairdressers and Beauticians (grant \# 150217).

Competing interests JFT is member of the advisory committee, The National Board of Industrial Injuries, Denmark.

Patient and public involvement Patients and/or the public were not involved in the design, or conduct, or reporting, or dissemination plans of this research.

\section{Patient consent for publication Not applicable.}

Ethics approval In Denmark, register and questionnaire studies do not require approval by committees on biomedical research ethics. The project was approved by the Knowledge Centre on Data Protection Compliance under the records of processing regarding health science research projects within the Capital Region of Denmark. (VD-2018-521).

Provenance and peer review Not commissioned; externally peer reviewed.

Data availability statement Data are available on reasonable request. Data from the JEM are available on reasonable request. Data from the Danish national registers are available through online access at Statistics Denmark under standard conditions.

Open access This is an open access article distributed in accordance with the Creative Commons Attribution Non Commercial (CC BY-NC 4.0) license, which permits others to distribute, remix, adapt, build upon this work non-commercially, and license their derivative works on different terms, provided the original work is properly cited, appropriate credit is given, any changes made indicated, and the use is non-commercial. See: http://creativecommons.org/licenses/by-nc/4.0/.

\section{ORCID iD}

Jonathan Aavang Petersen http://orcid.org/0000-0003-0635-4144

\section{REFERENCES}

1 Wong JJ, Côté P, Quesnele JJ, et al. The course and prognostic factors of symptomatic cervical disc herniation with radiculopathy: a systematic review of the literature. Spine J 2014;14:1781-9.

2 Zielinska N, Podgórski M, Haładaj R, et al. Risk factors of intervertebral disc Pathology-A point of view formerly and Today-A review. J Clin Med 2021;10:409.

3 Brinjikji W, Luetmer PH, Comstock B, et al. Systematic literature review of imaging features of spinal degeneration in asymptomatic populations. AJNR Am J Neuroradiol 2015;36:811-6.

4 Radhakrishnan K, Litchy WJ, O'Fallon WM, et al. Epidemiology of cervical radiculopathy. A population-based study from Rochester, Minnesota, 1976 through 1990. Brain 1994;117 (Pt 2:325-35.

5 Kolenkiewicz M, Włodarczyk A, Wojtkiewicz J. Diagnosis and incidence of spondylosis and cervical disc disorders in the University clinical hospital in Olsztyn, in years 2011-2015. Biomed Res Int 2018;2018:1-7.

$6 \mathrm{Kim}$ Y-K, Kang D, Lee I, et al. Differences in the Incidence of Symptomatic Cervical and Lumbar Disc Herniation According to Age, Sex and National Health Insurance Eligibility: A Pilot Study on the Disease's Association with Work. Int J Environ Res Public Health 2018;15:2094-9.

7 Mansfield M, Smith T, Spahr N, et al. Cervical spine radiculopathy epidemiology: a systematic review. Musculoskeletal Care 2020;18:555-67. 
8 Norasi H, Tetteh E, Sarker P, et al. Exploring the relationship between neck flexion and neck problems in occupational populations: a systematic review of the literature. Ergonomics 2021:1-17.

9 Hagberg M, Wegman DH. Prevalence rates and odds ratios of shoulder-neck diseases in different occupational groups. $\mathrm{Br} \mathrm{J}$ Ind Med 1987;44:602-10.

10 Huang C-C, Kuo P-J, Hsu C-C, et al. Risk for cervical herniated intervertebral disc in dentists: a nationwide population-based study. BMC Musculoskelet Disord 2019;20:189.

11 Mason KT, Harper JP, Shannon SG. Herniated nucleus pulposus: rates and outcomes among U.S. Army aviators. Aviat Space Environ Med 1996;67:338-40.

12 Johnston SL, Campbell MR, Scheuring R, et al. Risk of herniated nucleus pulposus among U.S. astronauts. Aviat Space Environ Med 2010;81:566-74.

13 Liu C, Huang C-C, Hsu C-C, et al. Higher risk for cervical herniated intervertebral disc in physicians: a retrospective nationwide population-based cohort study with claims analysis. Medicine 2016;95:e5055.

14 Yamaguchi JT, Hsu WK. Intervertebral disc herniation in elite athletes. Int Orthop 2019;43:833-40.

15 Jensen A, Kaerlev L, Tüchsen F, et al. Locomotor diseases among male long-haul truck drivers and other professional drivers. Int Arch Occup Environ Health 2008;81:821-7.

16 Jensen MV, Tüchsen F, Orhede E. Prolapsed cervical intervertebral disc in male professional drivers in Denmark, 1981-1990. A longitudinal study of hospitalizations. Spine 1996;21:2352-5.

17 Nordander C, Hansson Gert-Åke, Ohlsson K, et al. Exposureresponse relationships for work-related neck and shoulder musculoskeletal disorders--Analyses of pooled uniform data sets. Appl Ergon 2016;55:70-84.

18 Kaiser MG, Haid RW. Degenerative cervical myelopathy and radiculopathy. Cham: Springer International Publishing, 2019.

19 Anderst WJ, Donaldson WF, Lee JY, et al. Cervical motion segment contributions to head motion during flexionlextension, lateral bending, and axial rotation. Spine J 2015;15:2538-43.

$20 \mathrm{Yu}$ Y, Mao H, Li J-S, et al. Ranges of cervical intervertebral disc deformation during an in vivo dynamic Flexion-Extension of the neck. J Biomech Eng 2017;139:0645011-7.

21 Pedersen CB. The Danish civil registration system. Scand J Public Health 2011;39:22-5.

22 Flachs EM, Petersen SEB, Kolstad HA, et al. Cohort Profile: DOC*X: a nationwide Danish occupational cohort with eXposure data - an open research resource. Int J Epidemiol 2019;48:1413-1413k.

23 Petersson F, Baadsgaard M, Thygesen LC. Danish registers on personal labour market affiliation. Scand J Public Health 2011;39:95-8.

24 Jensen VM, Rasmussen AW. Danish education registers. Scand J Public Health 2011;39:91-4.

25 Petersen SB, Flachs EM, Svendsen SW, et al. Influence of errors in job codes on job exposure matrix-based exposure assessment in the register-based occupational cohort DOC*X. Scand J Work Environ Health 2020;46:259-67.

26 Heilskov-Hansen T, Svendsen SW, Frølund Thomsen J, et al. Sex differences in task distribution and task exposures among Danish house painters: an observational study combining questionnaire data with biomechanical measurements. PLoS One 2014;9:e110899.

27 Dalbøge A, Frost P, Andersen JH, et al. Surgery for subacromial impingement syndrome in relation to occupational exposures, lifestyle factors and diabetes mellitus: a nationwide nested casecontrol study. Occup Environ Med 2017;74:728-36.

28 Hoozemans MJ, Burdorf A, van der Beek AJ, et al. Group-Based measurement strategies in exposure assessment explored by bootstrapping. Scand J Work Environ Health 2001;27:125-32.

29 Hansson G-A, Asterland P, Kellerman M. Modular data logger system for physical workload measurements. Ergonomics 2003;46:407-15.

30 Arvidsson I, Hansson G-A, Mathiassen SE, et al. Neck postures in air traffic controllers with and without neck/shoulder disorders. Appl Ergon 2008;39:255-60.

$31 \mathrm{GÅ} \mathrm{H}$, Balogh I, Ohlsson K. Physical workload in various types of work: Part II. neck, shoulder and upper arm. Int J Ind Ergon 2010;40:267-81.

32 Lynge E, Sandegaard JL, Rebolj M. The Danish national patient register. Scand J Public Health 2011;39:30-3.

33 Kotkansalo A, Leinonen V, Korajoki M, et al. Surgery for degenerative cervical spine disease in Finland, 1999-2015. Acta Neurochir 2019;161:2147-59.

34 Kristiansen J-A, Balteskard L, Slettebø $\mathrm{H}$, et al. The use of surgery for cervical degenerative disease in Norway in the period 2008-2014 : A population-based study of 6511 procedures. Acta Neurochir 2016;158:969-74.

35 Armstrong BG. Effect of measurement error on epidemiological studies of environmental and occupational exposures. Occup Environ Med 1998;55:651-6.

36 Lama P, Le Maitre CL, Dolan P, et al. Do intervertebral discs degenerate before they herniate, or after? Bone Joint J 2013;95B:1127-33.

37 Kauppinen T, Heikkilä P, Plato N, et al. Construction of job-exposure matrices for the Nordic occupational cancer study (NOCCA). Acta Oncol 2009;48:791-800.

38 Marshall LW, McGill SM. The role of axial torque in disc herniation. Clin Biomech 2010;25:6-9.

39 Molladavoodi S, McMorran J, Gregory D. Mechanobiology of annulus fibrosus and nucleus pulposus cells in intervertebral discs. Cell Tissue Res 2020;379:429-44.

40 Hansson G-A, Arvidsson I, Ohlsson K, et al. Precision of measurements of physical workload during standardised manual handling. Part II: Inclinometry of head, upper back, neck and upper arms. J Electromyogr Kinesiol 2006;16:125-36.

41 Andresen AK, Paulsen RT, Busch F, et al. Patient-Reported outcomes and patient-reported satisfaction after surgical treatment for cervical radiculopathy. Global Spine J 2018;8:703-8.

42 Sambrook PN, MacGregor AJ, Spector TD. Genetic influences on cervical and lumbar disc degeneration: a magnetic resonance imaging study in twins. Arthritis Rheum 1999;42:366-72.

43 Heilskov-Hansen T, Mikkelsen S, Svendsen SW, et al. ExposureResponse relationships between movements and postures of the wrist and carpal tunnel syndrome among male and female house painters: a retrospective cohort study. Occup Environ Med 2016;73:401-8. 